\title{
Subjetividade e (re)produção escrita
}

Cristiane Carvalho de Paula Brito (BRITO, Cristiane C. P.)

Professora Doutora da Universidade Federal de Uberlândia - UFU

carvalhodepaula@yahoo.com

\section{Resumo}

Este trabalho ${ }^{1}$, fundamentado no dialogismo bakhtiniano e nos referenciais teóricos da Análise do Discurso de linha francesa tem o objetivo de analisar dissertações de vestibulandos, a fim de evidenciar como a subjetividade emerge ao longo do texto. A subjetividade nas redações será analisada por meio de três categorias: 1 . posicionamento - que nos permitirá evidenciar os recursos utilizados pelo sujeito ao se posicionar em relação ao tema (ou questões com este envolvidas) proposto para a dissertação; 2. retextualização - em que evidenciaremos os recursos utilizados pelo sujeito ao se relacionar com os trechos de textos apresentados na prova; e 3. estilo - que investigará o trabalho do sujeito com os aspectos meramente lingüísticos. De forma mais ampla, propomo-nos a repensar o ensino de escrita na escola, a partir de uma visão que considera a multiplicidade dos sentidos como fundamental em qualquer trabalho com a linguagem.

Palavras-chave: produção escrita; dissertação; subjetividade; heterogeneidade

\begin{abstract}
This work, based on the bakhtinian dialogism and on the principles of French Discourse Analyzis theory, aims at analyzing essays of candidates to university entrance examination, on the purpose of evidencing how subjectivity emerges along the text. The subjectivity in the essays will be analyzed through three categories: (1) positioning which will enable us to evidence the means used by the candidate when discussing the theme (or matters related to it) proposed to write the essay; (2) retextualization - which will enable us to evidence the means used by the candidate to relate to the texts presented in the examination; and (3) style - which will investigate the candidate's work with linguistic aspects. Finally, we can say that this research intends, to a greater extent, to consider the teaching of writing at school, starting from a vision that considers the multiplicity of sense as fundamental in any work dealing with language.
\end{abstract}

Keywords: writing; essay; subjectivity; heterogeneity

\footnotetext{
${ }^{1}$ Este trabalho faz parte das reflexões tecidas em nossa dissertação de Mestrado, na Universidade Estadual de Campinas, sob a orientação da Profa. Dra. Maria Augusta Bastos de Mattos e o apoio financeiro da CAPES.
} 


\section{Introdução}

“Meus alunos não sabem escrever!”, “Os textos são todos iguais!”, “A única diferença é a letra!"... Essas e outras proposições (ou exclamações!) ressoam nas falas de centenas de professores quando o assunto é redação. A produção escrita aparece ora como um verdadeiro obstáculo a ser vencido, ora como um alvo quase inatingível.

A escrita é apontada, em grande parte dos estudos dedicados à investigação de seu ensino/aprendizagem, mais como um processo de reprodução do que propriamente de criação ou produção. Nosso trabalho, entretanto, caminha no sentido de repensar a escrita como espaço de construção de sentidos. Mais especificamente, propomo-nos aqui a investigar a constituição da subjetividade em dissertações escritas por vestibulandos.

Vale ressaltar que a escolha do texto dissertativo deve-se ao fato de esse tipo de texto requerer um maior uso de recursos argumentativos, elevando, assim a chance da retomada dos lugares-comuns, dos clichês, etc, que, por sua vez, tendem a contribuir para o apagamento da subjetividade. E é isso que talvez torne o trabalho mais "arriscado", porém, ao mesmo tempo, mais interessante: a tentativa de encontrar, a partir de uma perspectiva discursiva aliada a algumas noções do dialogismo bakhtiniano, o diferente no mesmo; o "eu" no "outro", ou o "outro" no "eu".

\section{Sobre a escrita na escola}

Como determinante das condições de produção do tipo de texto que analisamos - dissertações de vestibular - está o discurso pedagógico (DP), já que ele é, em grande parte, o responsável pelo modo de ensino da escrita.

Orlandi (2001) mostra como, na escola, o ato de ensinar é feito pela inculcação, que, por sua vez, se fundamenta: (1) na quebra das leis do discurso, enunciadas por Ducrot (1972, apud ORLANDI, 2001, p. 17); (2) no “é porque é”; e (3) na cientificidade.

Em relação ao primeiro aspecto da inculcação, teríamos, na escola, a quebra das seguintes leis: (i) lei da informatividade, que se refere à necessidade do desconhecimento, por parte do ouvinte, do fato a ser informado; (ii) lei do interesse, que diz respeito à necessidade de interesse, por parte do ouvinte, em relação ao que será 
dito; e (iii) lei da utilidade, que se refere às razões para se falar, isto é, os motivos envolvidos em um ato de fala.

Para camuflar a quebra das leis do discurso, é comum que a escola recorra ao conceito de motivação. Assim, se o aluno não aprende é porque ele não está motivado; em outras palavras, o DP atribui ao aluno a responsabilidade pelo fracasso na escola.

Em relação ao segundo aspecto, o "é porque é", nota-se que o DP não explica as razões do objeto de estudo, restringindo-se ao "é porque é". Nesse sentido, o DP utiliza, no nível da linguagem sobre o objeto, os dêiticos, a objetalização, a repetição, as perífrases. E, ao nível da metalinguagem, usa as definições rígidas, os cortes polissêmicos etc.

O terceiro fator (a cientificidade) diz respeito ao fato de a informação transmitida pelo discurso pedagógico carregar consigo o status de ser científica, sendo este assegurado pela metalinguagem (em que se prioriza não o conhecimento do fato, mas a forma de procedimento, a via de acesso a ele) e pela apropriação do cientista feita pelo professor (em que o professor toma o lugar do cientista, mas o modo pelo qual tal apropriação ocorre é silenciado). O discurso pedagógico é, pois, um discurso que se pretende neutro, já que se recobre do status de cientificidade e se apresenta como se não tivesse sujeito, sendo puramente cognitivo e informacional (ORLANDI, 2001, p. 29).

Esses aspectos provocam o esvaziamento de sentido e propósito encontrado em grande parte das atividades de escrita (ou leitura) propostas pela escola, já que o DP caminha, exatamente, na direção contrária à emergência da subjetividade, pois promove o apagamento do conflito, da tensão, característica esta constitutiva da linguagem.

Coracini (1997), ao questionar a relação entre Língua Materna e Língua Estrangeira, observa a ausência de conflitos no espaço da sala de aula. Para ela, a escola abafa as diferentes vozes constitutivas do sujeito, tornando-o mero "repetidor" da voz do livro didático e/ou do professor. A autora questiona a noção de sujeito uno, fonte de seu dizer, consciente e logocêntrico veiculada por diferentes metodologias de ensino; e a noção estática e acabada de identidade (em sua visão existem momentos de identificações, já que o sujeito é sempre constituído pelo outro).

De fato, inúmeros trabalhos têm se dedicado a investigar a situação do ensino da escrita na escola ${ }^{2}$. E, apesar das mudanças teóricas no campo da Lingüística, ou de

\footnotetext{
${ }^{2}$ Ver, por exemplo, os trabalhos de Amaral (1996), Athayde Jr. (2001), Costa Val (1999), Capponi (2000), De Lemos (1977), Kleiman (1997), Fiad (1997), e Pécora (1999).
} 
reformulações nos Parâmetros Curriculares ${ }^{3}$, muitos estudos apontam que a escrita escolar não é mais que um mero exercício, dentre tantos outros, realizados na e para a escola.

Assim, colocamo-nos o desafio de investigar a emergência da subjetividade num espaço predominantemente marcado pela reprodução, pela homogeneidade, pelos lugares-comuns. Pretendemos compreender como um sujeito que, carregando sobre si todo o "peso" de uma concepção homogeneizante de escrita, tenta colocar-se não apenas como o redator de um texto, mas na a posição discursiva de construtor de sentidos.

Passemos, portanto, às análises.

\section{Sobre as condições de produção do corpus}

O nosso corpus se constitui de 60 dissertações produzidas no Vestibular da Unicamp (1999). A leitura dessas dissertações nos permitiu estabelecer as categorias de análise, que explicitaremos posteriormente.

O tema para a dissertação ${ }^{4}$ foi "500 anos de Brasil", e o candidato deveria obrigatoriamente redigir seu texto com base em um conjunto de fragmentos, denominados Coletânea, que lhe são apresentados ${ }^{5}$.

Com base na leitura das 60 dissertações, estabelecemos três categorias de análise - posicionamento, retextualização e estilo - que nos permitissem evidenciar a emergência da subjetividade, isto é, a relação do sujeito com a linguagem no processo de mobilizar certos sentidos. Vejamos.

\footnotetext{
${ }^{3}$ Conforme os Parâmetros Curriculares Nacionais, o ensino/aprendizagem de Língua Portuguesa deve basear-se na natureza dialógica, social e interativa da linguagem. Desta forma, "os conteúdos tradicionais de ensino de língua, ou seja, nomenclatura gramatical e história da literatura, são deslocados para um segundo plano. $\mathrm{O}$ estudo da gramática passa a ser uma estratégia para compreensão/interpretação/produção de textos e a literatura integra-se à área de leitura" (p.139).

${ }^{4}$ Vale ressaltar que, apesar de nosso corpus se constituir apenas dos textos dissertativos, o candidato podia escolher entre três tipos de texto: um texto dissertativo-argumentativo (tema A); um texto narrativo (tema B); e um texto argumentativo persuasivo (tema C). Todos abordavam a temática 'Brasil', mas com diferentes nuances.

${ }^{5}$ Ver em anexo a coletânea para o tema A.
} 


\section{Posicionamento}

Dentro dessa categoria, elencamos os recursos utilizados pelo candidato ao se posicionar em relação ao tema (ou questões com este envolvidas) proposto para a dissertação. Interessa-nos menos o fato de o candidato ter uma visão otimista ou pessimista do Brasil, do que a maneira como o candidato orienta o seu texto (e seu leitor, é claro) a uma determinada linha argumentativa.

Por concebermos a linguagem como essencialmente marcada por sua natureza heterogênea, privilegiaremos na análise do Posicionamento a presença da polifonia entendida aqui como a multiplicidade de vozes dentro de um mesmo texto. Assim, analisaremos como o sujeito estabelece e articula outras vozes em seu texto, a fim de se posicionar em relação ao tema.

Em nosso corpus, a polifonia se deu através de:

1.1 Recursos lingüísticos, tais como: uso de repetição; uso de intercalação; uso de sinal gráfico; e uso de aspas.

1.2 Uso de ironia, manifestada pelo uso de estrangeirismos; uso de neologismos; uso de aspas; e uso de intercalação.

1.3 Uso de ambigüidade.

1.4 Presença de intertextualidade - considerada como a citação explícita de um outro texto (exceto da coletânea).

1.5 Uso de conhecimento enciclopédico - concebido como as informações, presentes no texto dos candidatos, que não se encontram na coletânea.

1.6 Diálogo do sujeito com a sua fala.

1.7 Diálogo do sujeito com o seu interlocutor, por meio do uso de frases interrogativas; da antecipação da voz do interlocutor; do apelo ao interlocutor.

\section{Retextualização}

Nessa categoria analisamos os recursos utilizados pelo sujeito ao se relacionar com os fragmentos apresentados na prova. Interessa-nos saber como o candidato incorpora (aceitando ou rejeitando), em seu texto, os elementos do texto da prova, tendo sempre em vista a emergência de sua subjetividade.

Vale ressaltar que a retextualização requer uma interpretação; assim, é uma certa leitura de um fragmento que determinará a forma como este aparecerá no texto do 
sujeito. Bakhtin (2002, p. 195) ilustra isso ao afirmar que "as palavras do outro, introduzidas na nossa fala, são revestidas inevitavelmente de algo novo, da nossa compreensão e da nossa avaliação, isto é, tornam-se bivocais".

É necessário salientar que adotamos uma perspectiva que entende que "qualquer modificação na materialidade do texto corresponde a diferentes gestos de interpretação" (ORLANDI, 2004, p.14). Isto é, ainda que o candidato se posicione na mesma direção do texto motivador, por exemplo, o fato de dizer o que está posto com outras palavras, ressalta o movimento da língua com a exterioridade, com os já-ditos, enfim, com uma memória discursiva. E a forma com que o sujeito reorganiza esses já-ditos pode, a nosso ver, apontar para uma maior ou menor emergência da subjetividade.

A categoria Retextualização, que é, na verdade, um diálogo do locutor com os trechos da coletânea (e não deixa de ser um recurso polifônico), apareceu nas dissertações, através de:

2.1 Paráfrase - que consistiu na retomada do já-dito, de forma a manter a linha argumentativa do autor do fragmento em questão. Esta retomada fica, às vezes, no nível lingüístico, sendo que aparecem "estratégias de colagem" de um texto no outro, por meio do uso de inversões sintáticas; da troca de vocábulos e expressões lingüísticas; e da reformulação lingüística do texto fonte.

2.2 Refutação - aqui o candidato retoma o que foi dito na coletânea para estabelecer um ponto de vista contrário, isto é, para evidenciar uma linha argumentativa distinta da do fragmento em questão.

2.3 Ressignificação de fonte do fragmento.

2.4 Citação do autor do fragmento.

\section{Estilo}

Nessa categoria investigamos o trabalho do sujeito com os aspectos meramente lingüísticos, isto é, os recursos e estratégias, disponíveis ao sujeito em sua língua, utilizadas na constituição de seu texto, a fim de promover a multiplicidade de sentidos.

Não podemos, obviamente, generalizar afirmando que um determinado recurso é uma característica da escrita do candidato, pois para isso seria necessário investigar outras de suas produções. Nosso objetivo é, pois, somente analisar como, na produção escrita em questão, o candidato se relacionou com a língua a fim de produzir certos efeitos de sentido. 
Talvez possa surgir um questionamento em relação à coerência desta categoria com o referencial teórico no qual nos fundamentamos, portanto, faz-se necessário um esclarecimento.

Não tomamos estilo como a livre escolha do sujeito em relação à língua, e sim como uma forma de se reorganizar o já-dito. Possenti $(2001)^{6}$ mostra que o estilo tem sido geralmente considerado em sua concepção romântica, como expressão de uma subjetividade unitária, psicológica, em que se considera a estratégia do desvio e da escolha. Ele propõe que a escolha seja vista como "um efeito da multiplicidade dos recursos, que competem entre si a todo instante" (p. 16). É, pois, neste sentido que estamos recorrendo ao conceito de estilo.

Dentre os recursos encontrados nas dissertações na categoria de estilo, destacamos: repetição de palavras ou expressões; uso de enumeração; reformulação do já-dito; uso de frases interrogativas; uso de antíteses; uso de dois-pontos; uso de períodos curtos; uso de paralelismo; uso de primeira pessoa do singular; trabalho com a sonoridade; e jogo de palavras.

É preciso salientar que as categorias não são independentes umas das outras. Não tivemos, portanto, a pretensão de demarcar entre elas um limite rígido, a fim de criar uma "gramática da subjetividade". A sua construção deve-se ao fato de nos permitir explorar melhor certos aspectos do texto.

Redações produzidas em outro contexto, para um outro propósito, com um gênero distinto, certamente pediriam outras categorias, já que os textos seriam lidos de forma diferente.

\section{A emergência da subjetividade}

Analisaremos aqui duas dissertações como forma de explicitar nosso gesto de leitura. Salientamos que as redações foram transcritas tais como coletadas. 


\section{Redação 01 \\ QUE TOQUEM O DERRADEIRO TANGO ARGENTINO!}

Os ufanistas quixotescos estão felicíssimos: em abril do ano de 2000 o Brasil comemorará quinhentos anos de seu "descobrimento". A contagem regressiva já fora acionada e muitos, tomados por um repentino sentimento de amor à pátria, como em um passe de mágica esqueceram as deficiências e mazelas tupiniquins.

No entanto, não há tanto o que comemorar a não ser para os países do lado de lá do Equador. Estes devem estar eufóricos, afinal conseguiram - por 500 anos! - a façanha de explorar e enganar toda uma nação.

A embromação já começa em nosso "descobrimento": o Brasil não foi "descoberto" já que os portugueses sabiam muito bem o que procuravam e onde pretendiam chegar.

A partir daí o Brasil se transformara em um títere, condição que perdura até os nossos dias.

É desolador constatar que enquanto o tempo passa e corre e voa continuamos a caminhar em círculos. No contexto mercantilista éramos reles fornecedores de matéria-prima e mão-de-obra barata. Hoje ainda desempenhamos a mesma função, só que em meio a uma explosiva mistura de neoliberalismo com Globalização.

A nossa independência histórica não ocorreu na prática. Só por seu caráter sui generis deveríamos ter desconfiado de que não era séria: um membro da própria família real foi quem declarou o país independente e ainda assim sob uma constrangedora indenização à Inglaterra. Atualmente continuamos dependente de aplicações externas para cobrir o défict de nossa balança comercial e suprir a nossa demanda por tecnologia.

Faz-se mister ressaltar que, passados apenas 70 anos do movimento antropofágico - que tentou criar uma cultura original, de pura identidade nacional - estamos adotando uma cultura estrangeira em detrimento da nossa. Um nítido exemplo: todos os jovens comemoram o Halloween mas muitos nunca ouviram falar da Folia de Reis que ocorre em seis de janeiro e já fora uma festa típica brasileira. Em nosso itinerário histórico já vimos este mesmo episódio: os índios foram obrigados a relegar a sua cultura riquíssima para abraçar a dos colonizadores.

No plano interno pouco foi mudado: a estrutura fundiária continua absurda, a concentração de renda ainda forma um íngreme abismo entre aqueles magnatas $e$ os "sem-tudo", o Brasil continua sendo um país nepotista e coorporativista que trabalha em favor das super-potências, seus parasitas.

Quiçá esta situação ainda possa ser revertida.

Esperemos esta ajuda do FMI, a panacéia utópica desejada.

Mas ao que tudo indica, o caminho destinado ao Brasil não terá volta.

\footnotetext{
${ }^{6} \mathrm{O}$ artigo de Possenti (2006) propõe-se a mostrar que os conceitos de enunciação, autoria e estilo podem ser compatibilizados entre si e com a AD.
} 
Uma flor - o Brasil - romperia o asfalto - condição inexorável de colônia. Mas que pena! - havia uma pedra no meio do caminho...

Que venha então o tango argentino.

O sujeito enunciador assume uma posição pessimista, em sua linha argumentativa, manifestada polifonicamente, através do uso de aspas, nos vocábulos "descobrimento" e "descoberto", relativizando a voz histórico-social que enuncia o descobrimento do Brasil.

Observa-se ainda a presença da ironia, através do uso de intercalação - a fim de introduzir a voz avaliativa do dissertador, em "por 500 anos!" e "que pena!" - e do uso de neologismo "sem-tudo", retomando a questão da desigualdade social marcada pelos sem-terra.

Há também exemplo de ironia, depreendida pelo contexto, como em "Quiçá esta situação ainda possa ser revertida. Esperemos esta ajuda do FMI, a panacéia utópica desejada".

Além disso, na categoria Posicionamento, podemos destacar o uso de intertextualidade ("Mas - que pena! - havia uma pedra no meio do caminho..."), remetendo-nos, ironicamente, ao discurso poético.

Nota-se o uso de conhecimento enciclopédico, marcado nas expressões "ufanistas quixotescos"; “contagem regressiva", "movimento antropofágico", "Halloween", "Folia de Reis", "FMI".

Finalmente, é interessante apontar o uso de vocábulos de cunho avaliativo, que claramente marcam a posição do sujeito, a saber: "ufanistas quixotescos", "façanha", “embromação", “desolador", "reles fornecedores", "parasitas".

Quanto à categoria Retextualização, não há uso explícito dos fragmentos da coletânea, de fato, esta aparece apenas como temática no texto.

Já na categoria Estilo, vemos a constituição da subjetividade, através de vários recursos que permitem o estabelecimento de um vínculo intersubjetivo no texto. Tem-se o uso de dois pontos, a fim de marcar, na escrita, uma sensível suspensão da voz na melodia de uma frase não concluída, como em "Os ufanistas quixotescos estão felicíssimos: em abril do ano de 2000 o Brasil comemorará quinhentos anos de seu “descobrimento"; "Só por seu caráter sui generis deveríamos ter desconfiado de que não era séria: um membro da própria família real foi quem declarou o país independente e..."; “... estamos adotando uma cultura estrangeira em detrimento da nossa. Um nítido 
exemplo: todos os jovens comemoram o Halloween mas muitos nunca ouviram falar da Folia de Reis..."; "No plano interno pouco foi mudado: a estrutura fundiária continua absurda, a concentração de renda ainda forma um íngreme abismo entre aqueles magnatas e os "sem-tudo"”.

Nota-se ainda o uso de períodos curtos, provocando o efeito de universalidade e verdade dos enunciados, como em: "A partir daí o Brasil se transformara em um títere, condição que perdura até os nossos dias"; "Quiçá esta situação ainda possa ser revertida"; "Esperemos esta ajuda do FMI, a panacéia utópica desejada"; "Mas ao que tudo indica, o caminho destinado ao Brasil não terá volta"; "Que venha então o tango argentino".

Vejamos a segunda dissertação.

\section{Redação 02}

\section{BRASIL REAL}

Atualmente, às vésperas da comemoração dos 500 anos da descoberta do nosso país, qual a situação do Brasil e quem somos?

Em primeiro lugar, o Brasil considerado país do futebol, tem um outro lado mais real. Somos um povo, que em grande parte está desempregado e que por outro lado, profissionais com o curso superior são faxineiros nas indústrias. Com a má educação que recebemos, fica difícil termos bons empregos e uma vida digna. $O$ Brasil tem uma riqueza aparente, no qual o dinheiro se concentra em uma pequena parcela da população, igualmente comparado com o Brasil colônia, em que a riqueza se concentrava nas mãos dos senhores de engenho e a maioria da população era pobre e faminta.

Em segundo lugar, um povo que tem uma má educação não é um povo culto e nem original. Se na época do Brasil colonia eramos influenciados pela cultura européia, em que a "moda" era usar roupas inglesas, hoje somos um povo influenciado pelas potências mundiais, no qual as crianças brincam de "cowboy" depois de jantar "hamburguer e coca cola".

Em terceiro lugar, essa situação de desemprego, fome, violencia e doenças que o Brasil se encontra, provavelmente deve-se ao tipo de colonização que nós recebemos, a colonização exploração. Se tivessemos recebido um outro tipo de colonização, de outra nação por exemplo, talvez hoje nossa situação seria melhor. Doenças e a escravidão trazida pelos colonizadores portugueses e espanhóis fez a devastação dos nossos índios.

Em quarto lugar, somos um povo, uma nação que tem uma enorme constituição, com numerosas leis. Porém que não fazem efeitos algum. Estão apenas no papel, dificultando também o nosso dever e direito de sermos cidadãos. Deixando para nós uma "cidadania de papel", ou seja, só na constituição.

Por fim, somos um povo que vive uma situação "moldada, fruto" do nosso passado. Nós vivemos os efeitos de uma má colonização e administração passadas. 
Para mudar esse panorama devemos lutar com seriedade, para que então o nosso futuro seja diferente do nosso passado e presente.

Percebe-se, nessa dissertação, como na anterior, uma visão pessimista quanto ao tema em questão, e, em relação à categoria Posicionamento, notamos a emergência da subjetividade, por meio do uso da ironia, expressa pelo uso de estrangeirismos, os quais parecem americanizar o discurso, e trazer à tona um outro lugar (o lugar do estrangeiro), uma outra voz (como se percebe em “... hoje somos um povo influenciado pelas potências mundiais, no qual as crianças brincam de "cowboy" depois de jantar "hamburguer e coca cola"”).

Nota-se, ainda, o uso de conhecimento enciclopédico, que permite ao sujeito expressar sua crítica à constituição, marcada na expressão "cidadania de papel"7 .

Na categoria Retextualização, também notamos a tentativa do sujeito de fazer da escrita um espaço de construção de sentidos. De fato, o diálogo com a coletânea se dá através de:

1. Paráfrase do fragmento 02 - o segundo parágrafo não apenas confirma as idéias expostas no segundo fragmento, mas apresenta um outro foco para a questão; como se pode perceber, no texto do candidato a ênfase recai sobre o aspecto da "má educação", enquanto no fragmento se enfatiza a exploração (“Com a má educação que recebemos, fica difícil termos bons empregos e uma vida digna")

2. Refutação do terceiro fragmento - o terceiro parágrafo é um contraponto ao terceiro fragmento da coletânea (hoje somos um povo influenciado pelas potências mundiais), e também um reforço ao segundo (não é um povo culto e nem original):

Em segundo lugar, um povo que tem uma má educação não é um povo culto $e$ nem original. Se na época do Brasil colonia eramos influenciados pela cultura européia, em que a "moda" era usar roupas inglesas, hoje somos um povo influenciado pelas potências mundiais, no qual as crianças brincam de "cowboy" depois de jantar "hamburguer e coca cola".

\footnotetext{
${ }^{7} \mathrm{O}$ termo "cidadania de papel" é provavelmente uma referência à obra $O$ cidadão de papel: a infância, $a$ adolescência e os direitos humanos, de Gilberto Dimenstein
} 
3. Refutação do quinto fragmento - o candidato não vê a colonização portuguesa como positiva, como se percebe no trecho: "Se tivessemos recebido um outro tipo de colonização, de outra nação por exemplo, talvez hoje nossa situação seria melhor. Doenças e a escravidão trazida pelos colonizadores portugueses e espanhóis fez a devastação dos nossos índios”.

4. Refutação do oitavo fragmento, como vemos no quinto parágrafo do texto, em: "Em quarto lugar, somos um povo, uma nação que tem uma enorme constituição, com numerosas leis. Porém que não fazem efeitos algum”.

Além desses recursos, vemos que a introdução dessa dissertação é um diálogo com o parágrafo introdutório da coletânea (e não deixa de ser também um diálogo com o interlocutor). A orientação para que se faça uma reflexão sobre quem somos hoje aparece no texto do candidato em forma de pergunta: "Atualmente, às vésperas da comemoração dos 500 anos da descoberta do nosso país, qual a situação do Brasil e quem somos?”.

Assim, ao trabalhar com os fragmentos que lhe são apresentados, o candidato se coloca como sujeito do que diz, exerce um trabalho sobre/na e, obviamente, pela linguagem.

No que diz respeito à categoria de Estilo, podemos perceber o estilo didático. De fato, o texto parece aproximar-se do modelo de dissertação apresentado pelos livros, com exceção, talvez, da introdução. Interessante notar o uso dos marcadores ( $\mathrm{em}$ primeiro lugar, em segundo lugar, em terceiro lugar, em quarto lugar, por fim), a fim de dar a aparência de cientificidade.

De modo geral, nossas análises apontam que, na categoria Posicionamento, prevalece uma visão pessimista do assunto e, diante de uma primeira leitura poderíamos dizer que as dissertações têm um caráter monológico. Todavia, as análises nos permitem resgatar nos textos a emergência de outras vozes, "momentos de polifonia", talvez diríamos. O que parece faltar a alguns são leituras para trazer vozes que não a do sensocomum, o que permitiria uma reflexão mais profunda do tema.

Além disso, o fato de o sujeito se posicionar unicamente de forma pessimista (ou otimista) não é suficiente para considerar sua produção escrita como monológica. $\mathrm{Na}$ verdade, o essencial é observar como o sujeito tece seus argumentos no texto. Em outras palavras, uma visão balanceada, mas simplesmente fundamentada em lugares-comuns positivos ou negativos - não deixaria de ser monológica, no sentido em que prioriza a voz do senso-comum. 
Na categoria Retextualização é que a emergência da subjetividade aparece com mais consistência, talvez, pelas próprias condições de produção do texto. Aqui vemos a tentativa do sujeito em tornar seu texto um espaço polifônico, através do diálogo com outros textos. Percebe-se, pois, que o "outro" é parte essencial do "eu”, não apenas uma "lembrança"... Afinal, um texto não pode sair do nada, como muitas vezes quer a escola; é preciso se ter algo a dizer a alguém. Nos casos, por exemplo, em que os candidatos fogem do tema da dissertação, ainda assim são às palavras do outro que eles recorrem. $^{8}$

Dentre os recursos utilizados nesta categoria, a paráfrase aparece como o mais recorrente, o que, provavelmente, aponte a dificuldade do sujeito de articular um contraargumento ao discurso do outro, isto é, de tomar o discurso do outro para refutá-lo, mesmo porque tal procedimento, embora apresentado, nos livros didáticos, como recurso a ser utilizado no desenvolvimento do texto dissertativo, não se enquadra no perfil do discurso pedagógico. O aluno é ensinado a acatar o discurso do outro (do livro, do professor, da instituição).

Percebe-se ainda que, apesar da presença do diálogo dos textos-fonte com o texto dos candidatos, poucos são os sujeitos que explicitamente consideram o autor do fragmento em questão. Cremos que tal fato reflita o ensino escolar da escrita, em que, praticamente, não há consideração pelas condições de produção, nem mesmo pelas condições mais imediatas, como o autor do texto. A coletânea aparece, pois, mais como uma fonte de informação para o candidato.

A categoria Estilo, por sua vez, demonstrou ser a de maior eficácia no apagamento da subjetividade. De fato, o que predomina aqui é o estilo didático, que preza por uma linguagem "precisa", "objetiva" e "impessoal" - conforme a orientação do livro didático. O aluno pode até fugir do tema, mas dificilmente fugirá da forma. Afinal, são vários anos de treinamento...

Há de se ressaltar que o fato de as dissertações serem produzidas em um contexto de avaliação talvez contribua para a não emergência da subjetividade, já que o receio de "ousar demais" e não preencher as expectativas da banca examinadora é um fator a ser considerado.

\footnotetext{
${ }^{8}$ Interessante notar que as dissertações que não apresentam um diálogo explícito com a Coletânea, como
} 


\section{Considerações Finais}

As análises apontam para um aspecto fundamental na produção de um texto: a representação do interlocutor. Apesar de a argumentação ser uma característica da linguagem, no texto dissertativo, por ser seu objetivo a defesa de uma idéia (uma tese), ou o questionamento de um determinado ponto de vista, os recursos argumentativos são mais nítidos do que em textos com propósitos diferentes.

E como a argumentação é produzida por um sujeito e dirigida a outro(s), as formações imaginárias (PÊCHEUX, 1997), isto é, as representações que o locutor faz de si mesmo, do interlocutor e do objeto discursivo, são de extrema relevância. De fato, é justamente esse jogo de projeções que vai determinar a seleção e articulação dos argumentos (ou contra-argumentos) utilizados no texto.

Nesse sentido, a forma pela qual o sujeito se posiciona, retextualiza e trabalha com aspectos lingüísticos - visando um determinado estilo - se relaciona, dentre outras, à imagem que o locutor tem do seu interlocutor, e com a imagem que o locutor tem da imagem que o interlocutor tem do objeto discursivo.

Percebe-se que, nas redações, o interlocutor aparece representado ora como um avaliador, ora como um leitor. Para o primeiro interessariam as regras do jogo, para o segundo a construção de significados por meio do texto.

Se a imagem do locutor é a primeira, a emergência da subjetividade está comprometida, já que esta imagem é, em grande parte, responsável pela consolidação de uma escrita homogênea.

A representação do interlocutor como avaliador/leitor é manifestada, sobretudo, naquilo que o aluno escolhe (ou não) explicitar. Em algumas dissertações, é como se o interlocutor não tivesse acesso à coletânea - nos casos, por exemplo, em que há uma simples paráfrase de fragmentos - nem a discursos correntes na sociedade. Desta forma, o que se torna relevante é comprovar ao interlocutor que há o domínio de uma forma, e não fazer do texto um espaço que possibilite a mobilização de sentido e a construção de significados.

Neste sentido, a análise nos permite concluir que não é a presença de informações, ou de bons argumentos (já que estamos falando de textos dissertativos) em um texto que o torna bom, mas a capacidade do sujeito em articular diversas vozes. Ao

na primeira redação, evidenciam o uso de conhecimento enciclopédico. 
discutir a concepção do que venha a ser um bom texto, Possenti (1994) afirma que não é "uma invulgar novidade ou uma radical criatividade" ou tampouco "a monótona repetição dos lugares-comuns" que o caracteriza, mas o conceber o discurso como radicalmente marcado pela heterogeneidade e a polifonia.

É preciso, pois, promover um ensino de escrita que possibilite a criação de textos únicos. Há uma direção para que isso aconteça: trata-se de pensar a linguagem como polifônica e os sujeitos como heterogêneos; em outras palavras, trata-se de aceitar o diferente, não apagar os conflitos, ainda que esta lição não esteja prevista em uma unidade do livro didático.

\section{Referências}

AMARAL, Nair F. G. Clichês em redações do vestibular: estratégias discursivas. Dissertação (Mestrado em Linguística Aplicada) - Instituto de Estudos da Linguagem, UNICAMP, Campinas, 1996.

ATHAYDE JÚNIOR, Mário C. Outras mesmas palavras: paráfrase discursiva em redações de concurso. Cascavel: EDUNIOESTE, 2001.

BAKHTIN, Mikhail. O discurso em Dostoiévski. In: Problemas da poética de Dostoiévski. Rio de Janeiro: Forense Universitária, 2002.

BRASIL, Secretaria de Educação Fundamental. Parâmetros Curriculares Nacionais: língua portuguesa - $2^{\circ}$. Brasília, DF, 1999.

CAPPONI, Maria Graciléia. A escrita na escola: apre(e)ndendo as regras do jogo. Dissertação (Mestrado em Linguística Aplicada) - Instituto de Estudos da Linguagem, UNICAMP, Campinas, 2000.

CORACINI, Maria José R. F. Língua estrangeira e língua materna: uma questão de sujeito e identidade. Letras \& Letras, v. 14, n. 1, p. 153-169, 1997.

COSTA VAL, Maria da Graça. Redação e textualidade. 2. ed. São Paulo: Martins Fontes, 1999.

DE LEMOS, Cláudia T. G. Redações no vestibular: algumas estratégias. Cadernos de Estudos Lingüísticos, v. 23, p. 61-71, 1997.

DUCROT, O. Princípios de semântica lingüística (dizer e não dizer). São Paulo: Cultrix, 1972.

FIAD, Raquel. O Estilo escolar. In: ABAURRE, Maria Bernadete M.; FIAD, Raquel; MAYRINK-SABINSON, Maria Laura T. (Orgs.). Cenas de aquisição da escrita: o 
sujeito e o trabalho com o texto. Campinas: Mercado de Letras/Associação de Leitura do Brasil - ALB, 1997, p. 195-204.

KLEIMAN, Angela B. Análise e produção de textos. In: PEREIRA, Maria Teresa G. (Org.). Lingua e linguagem em questão. Rio de Janeiro: EDUERJ, 1997. p. 262-283.

ORLANDI, Eni P. A linguagem e seu funcionamento: as formas do discurso. 4. ed. Campinas, SP: Pontes, 2001.

Interpretação: autoria, leitura e efeitos do trabalho

simbólico. 4. ed. Campinas, SP: Pontes, 2004.

PÉCORA, Alcir. Problemas de redação. 5. ed. São Paulo: Martins Fontes, 1999.

PÊCHEUX, Michel. Análise automática do discurso. In: GADET, Françoise; HAK, Tony. (Orgs.) Por uma análise automática do discurso: uma introdução à obra de Michel Pêcheux. 3. ed. Tradução de Bethania S. Mariani [et al.]. Campinas, SP: Editora da Unicamp, 1997. p. 61-105.

POSSENTI, Sírio. Discurso, sujeito e o trabalho de escrita. In: NASCIMENTO, Edna Maria F. S.; GREGOLIM, Maria do Rosário V. Problemas atuais da análise do discurso. Série Encontros, v. 1, Araraquara: Editora da Unesp, 1994. p. 27-41.

Enunciação, autoria e estilo. Revista da FAEEBA, v. 15. Salvador, p.15-21, 2001.

PRÓ-REITORIA DE GRADUAÇÃO. Dissertações do vestibular Unicamp-99. Campinas, SP: Editora da Unicamp,1999.

\section{Apêndice}

Este apêndice traz os fragmentos da prova de redação (Tema A) do Vestibular da Unicamp (1999), apresentados para os candidatos.

\section{TEMA A}

O Brasil está em vias de completar cinco séculos de existência aos olhos do mundo europeu. São os já conhecidos 500 anos de seu descobrimento, que serão comemorados oficialmente em abril de 2000. Como em qualquer data importante, o momento é oportuno para um balanço e uma reflexão. $\mathrm{O}$ balanço poderia resultar muito parcial, se se prendesse exclusivamente a fatos econômicos e a dados sociais circunstanciais. Por isso, faz-se necessário, neste caso, considerar a questão de quem somos hoje. Tendo isso em mente, e contando com o apoio obrigatório dos fragmentos abaixo, escreva uma dissertação sobre o tema

500 anos de Brasil 
1. Esqueça tudo o que você aprendeu na escola sobre o descobrimento do Brasil. (...) A dois anos das comemorações oficiais pelos 500 anos de descobrimento do Brasil, os últimos trabalhos de pesquisadores portugueses, espanhóis e franceses revelam uma história muito mais fascinante e épica sobre a chegada dos colonizadores portugueses ao Novo Mundo. O primeiro português a chegar ao Brasil foi o navegador Duarte Pacheco Pereira, um gênio da astronomia, navegação e geografia e homem da mais absoluta confiança do rei de Portugal, d. Manuel I. Duarte Pacheco descobriu o Brasil um ano e meio antes de Cabral, entre novembro e dezembro de 1498. (...) As novas pesquisas sobre a verdadeira história do descobrimento sepultam definitivamente a inocente versão ensinada nas escolas de que Cabral chegou ao Brasil por acaso, depois de ter-se desviado da sua rota em direção às Índias. (ISTOÉ, 26 de novembro de 1997.)

2. ... a despeito de nossa riqueza aparente, somos uma nação pobre em sua generalidade, onde a distribuição do dinheiro é viciosa, onde a posse das terras é anacrônica. Aquele anda nas mãos dos negociantes estrangeiros; estas sob o tacão de alguns senhores feudais. A grande massa da população, espoliada por dois lados, arredada do comércio e da lavoura, neste país essencialmente agrícola, como se costuma dizer, moureja por ali abatida e faminta, não tendo outra indústria em que trabalhe; pois que até os palitos e os paus de vassoura mandam-lhe vir do estrangeiro.

(...) povo educado, como um rebanho mole e automático, sob a vergasta do poder absoluto, vibrada pelos governadores, vice-reis, capitães-mores e pelos padres da companhia; povo flagelado por todas as extorsões - nunca fomos, nem somos ainda uma nação culta, livre e original. (Romero, Sílvio. História da Literatura Brasileira. 1881.)

3. O Brasil surge e se edifica a si mesmo, mas não em razão do desígnio de seus colonizadores. Eles só nos queriam como feitoria lucrativa. Contrariando as suas expectativas, nos erguemos, imprudentes, inesperadamente, como um novo povo, distinto de quantos haja, deles inclusive, na busca de nosso ser e de nosso destino. (...) Somos um povo novo, vale dizer um gênero singular de gente marcada por nossas matrizes, mas diferente de todas, sem caminho de retorno a qualquer delas. Esta singularidade nos condena a nos inventarmos a nós mesmos, uma vez que já não somos indígenas, nem transplantes ultramarinos de Portugal ou da África. (Ribeiro, Darcy. O Brasil como problema.1995.)

4. Não conhecemos proletariado, nem fortunas colossais que jamais se hão de acumular entre nós, graças aos nossos hábitos e sistema de sucessão. Nem argentarismo, pior que a tirania, nem pauperismo, pior que a escravidão.

(...)

O Brasil jamais provocou, jamais agrediu, jamais lesou, jamais humilhou outras nações.

(...)

A estatística dos crimes depõe muito em favor dos nossos costumes. Viaja-se pelo sertão sem armas, com plena segurança, topando sempre gente simples, honesta, serviçal.

Os homens de Estado costumam deixar o poder mais pobres do que nele entraram. Magistrados subalternos, insuficientemente remunerados, sustentam terríveis lutas obscuras, em prol da justiça, contra potentados locais. (...) Quase todos os homens políticos brasileiros legam a miséria a suas famílias. (Affonso Celso. Porque me ufano de meu país. 1900.)

5. (...) Se tu vencesses Calabar! / Se em vez de portugueses, / - holandeses!? / Ai de nós! / Ai de nós sem as coisas deliciosas que em nós moram: / redes, / rezas, / novenas, / procissões, - / e essa tristeza, Calabar, / e essa alegria danada, que se sente / subindo, balançando, a alma da gente. / Calabar, tu não sentiste / essa alegria gostosa de ser triste! (Lima, Jorge de. Poesia Completa, vol. 1.)

6. O pau-brasil foi o primeiro monopólio estatal do Brasil: só a metrópole podia explorá-lo (ou terceirizar o empreendimento). Seria, também, o mais duradouro dos cartéis: a exploração só foi aberta à iniciativa privada em 1872, quando as reservas já haviam escasseado brutalmente. 
Exploração não é o termo: o que houve foi uma devastação, com a derrubada de 70 milhões de árvores. Como que confirmando a vocação simbólica, o pau-brasil seria usado, em setembro de 1826, para o pagamento dos juros do primeiro empréstimo externo tomado pelo Brasil. Ao deparar com o Tesouro Nacional desprovido de ouro, d. Pedro I enviou à Inglaterra 50 quintais (3t) de toras de pau-brasil para leiloá-las em Londres. A esperança do Imperador de saldar a dívida com o "pau-de-tinta" esbarrou numa inovação tecnológica: o advento da indústria de anilinas reduzira em muito o valor da árvore-símbolo do Brasil. Os juros foram pagos com atraso. Em dinheiro, não em paus. (Bueno, E. (org). História do Brasil. Empresa Folha da Manhã. $2^{\mathrm{a}}$ ed. 1997.)

7. Jamais se saberá com certeza, mas quando os portugueses chegaram à Bahia, os índios brasileiros somavam mais de 2 milhões - quase três, segundo alguns autores. Agora, dizimados por gripe, sarampo e varíola, escravizados aos milhares e exterminados pelas guerras tribais e pelo avanço da civilização, não passam de 325.652 - menos do que dois Maracanãs lotados. (...) A idade média dos índios brasileiros é de 17,5 anos, porque mais da metade da população tem menos de 15 anos. A expectativa de vida é de 45,6 anos, e a mortalidade infantil é de 150 para cada mil nascidos. Existem pelo menos 50 grupos que jamais mantiveram contato com o homem branco, 41 dos quais nem sequer se sabe onde vivem, embora seu destino já pareça traçado: a extinção os persegue e ameaça. (Bueno, E. (org). História do Brasil. Empresa Folha da Manhã. $2^{\mathrm{a}}$ ed. 1997.)

8. Há um Código de Defesa do Consumidor, há leis que cuidam do racismo, do direito de greve, dos crimes hediondos, do juizado de pequenas causas, do sigilo da conversação telefônica, da tortura, etc. O país cresceu. (Carvalho Filho, L. F. Folha de S. Paulo. 3 de outubro de 1998.) 